\title{
A New Arteriovenous Fistula Model to Study the Development of Neointimal Hyperplasia
}

\author{
Eddie Manning ${ }^{a} \quad$ Nikolaos Skartsis $^{a} \quad$ Armando M. Orta ${ }^{a}$ Omaida C. Velazquez ${ }^{a}$ \\ Zhao-Jun Liu $^{a}$ Arif Asif ${ }^{b}$ Loay H. Salman ${ }^{b}$ Roberto I. Vazquez-Padron ${ }^{a}$

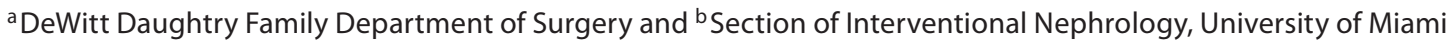 \\ Leonard M. Miller School of Medicine, Miami, Fla., USA
}

\section{Key Words}

Arteriovenous fistula $\cdot$ Neointima $\cdot$ Animal model .

Dialysis · Rat

\begin{abstract}
This study describes an alternative arteriovenous fistula (AVF) model in the rat in which the animals develop significant neointimal hyperplasia (NIH) not only at the distal anastomotic site, but also throughout the fistula body. This aortocaval fistula was established by anastomosing the distal end of the renal vein to the abdominal aorta after unilateral nephrectomy. The increased hemodynamic stress resulting from exposing the renal vein to the arterial circulation induced venous NIH as early as 7 days after surgery. This experimental AVF was characterized by the early lack of endothelium, the accumulation of proliferating vascular smooth muscle cells and the neovascularization of the fistula adventitia. In summary, we have described an informative animal model to study the pathobiology of $\mathrm{NIH}$ in native AVF.
\end{abstract}

Copyright $\odot 2012$ S. Karger AG, Basel
(C) 2012 S. Karger AG, Basel

$1018-1172 / 12 / 0492-0123 \$ 38.00 / 0$

Accessible online at:

www.karger.com/jvr

\section{Introduction}

Early failure of a newly created arteriovenous fistula (AVF) is a major clinical problem. It is associated with significant morbidity among the hemodialysis population and has been implicated as a cause of increased reliance on tunneled hemodialysis catheters [1]. Indeed, vascular access complications represent an enormous economical burden that exceeds USD 1 billion per year in the USA alone [2]. The single most important reason for vascular access dysfunction is stenosis as a result of neointimal hyperplasia (NIH) [3, 4]. At a histological level, NIH can be seen as an exaggerated accumulation of myofibroblasts and smooth muscle cells (SMCs) in the inner layer of the vein [5]. Despite the urgent need for effective therapies to keep vascular access free of neointima to maintain longer patency time, little is known about the pathobiology of NIH in vascular access.

Gaining insight into the disease process leading to AVF stenosis secondary to NIH requires informative animal models. Rodents are ideal for mechanistic studies because of the availability of numerous biological tools and resources for these species. AVFs with very limited

Dr. Roberto I. Vazquez-Padron

Department of Surgery

University of Miami Leonard M. Miller School of Medicine

1600 NW 10th Avenue, RMSB 7147A, Miami, FL 33136 (USA)

Tel. +1 305243 1154, E-Mail rvazquez@ med.miami.edu 

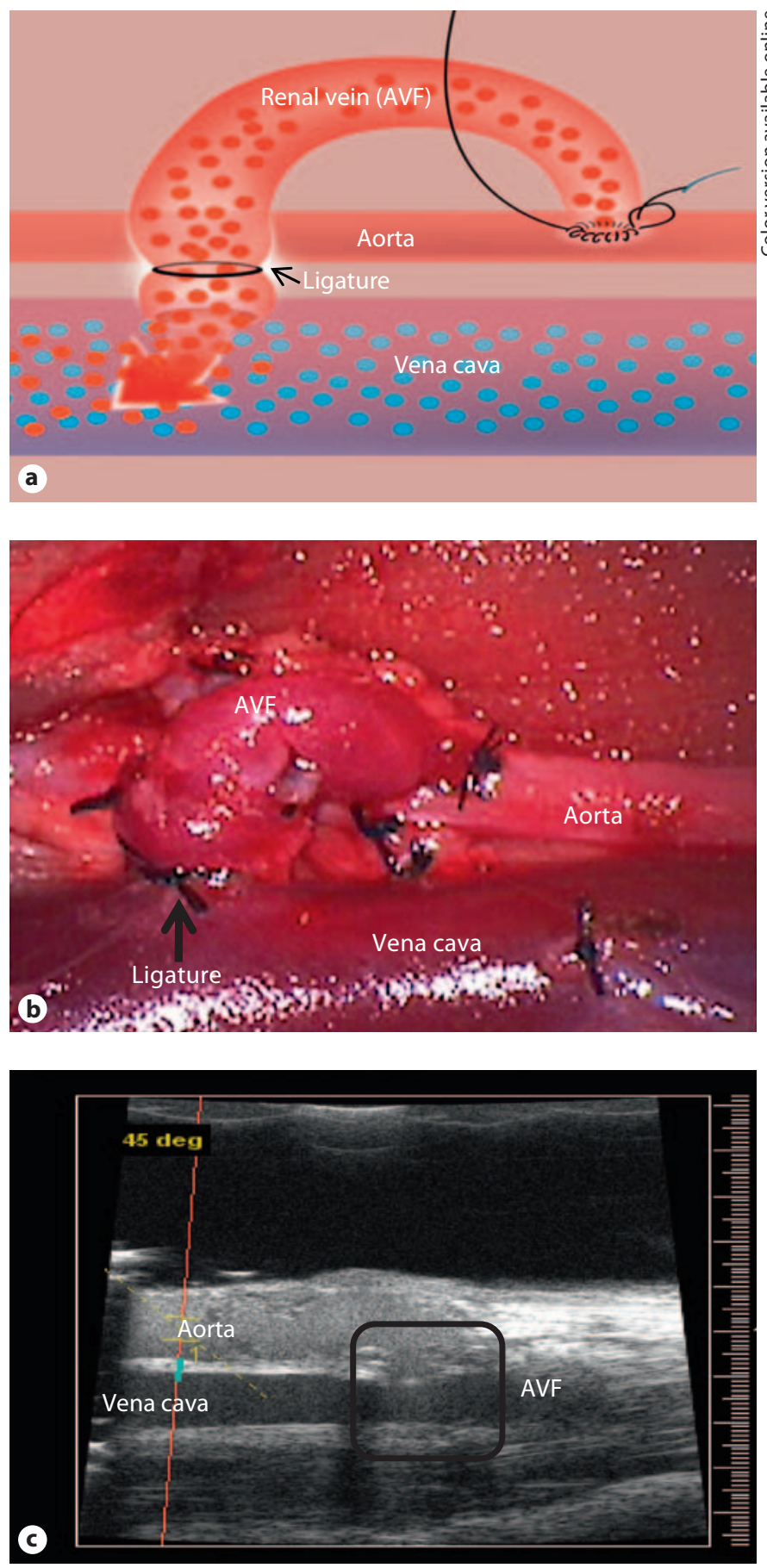

Fig. 1. a Diagrammatic representation of the AVF. Fistulae were created in rats by anastomosing the left renal vein to the abdominal aorta after unilateral nephrectomy. In this model, blood circulates from the aorta to the renal vein and then to the inferior vena cava. b Photograph of the aortocaval fistula after anastomosis. The arrow identifies the ligature at the distal renal vein to restrict blood flow. c Imaging of the AVF using ultrasound biomicroscopy. The AVF appears inside the box.
NIH have been described in mice and rats [6-11]. The present study describes an alternative experimental AVF that recapitulates the aggressive neointimal formation observed in dysfunctional human AVFs.

\section{Animals and Methods}

\section{Animals and Surgical Procedures}

Male Sprague Dawley rats (2-4 months old, Harlan Sprague Dawley Inc., Indianapolis, Ind., USA) were operated on under isoflurane anesthesia (Webster Veterinary, Ocala, Fla., USA). The abdominal cavity was accessed through a midline incision from the xiphoid process to the symphysis pubis. Retractors were placed to maintain exposure. The abdominal content was reflected to the right to expose the inferior vena cava, aorta and the left kidney. The intestines were wrapped in saline- soaked gauze to keep them moist and warm. The Gerota's fascia of the left kidney was incised using an electrocautery, and the renal artery and the ureter were both ligated with 8.0 prolene suture (Ethicon, San Lorenzo, P.R., USA). The renal vein was occluded with a $2-\mathrm{mm}$ microvascular clamp, and the left kidney was amputated at the distal renal vein. In the sham-operated animals (control), the renal vein was totally ligated as described above. In AVF-carrying animals, the infrarenal aorta was dissected from the inferior vena cava, and a curved vascular clamp was placed in the free aorta to maintain proximal and distal vascular control. An arteriotomy approximately $1 \mathrm{~mm}$ in length was created with microvascular scissors, and the lumina of the aorta and renal vein were flushed with saline and heparin. The anastomosis of the distal end of the renal vein to the aorta was performed using interrupted suturing with a 10.0 monofilament suture (Ethicon). Following completion of the anastomosis, the venous and arterial clamps were removed and bleeding was assessed. In case of leakage, interrupted 10.0 monofilament suture was used. Before reestablishing blood flow, a 23-gauge needle was placed adjacent to the distal renal vein and a 6-0 silk suture ligature was applied around it. The needle was then removed to create an immediate $>50-75 \%$ luminal stenosis (fig. 1a, b). The abdomen was irrigated with sterile normal saline, and all abdominal contents were placed in their normal anatomical position. Closure of the abdominal cavity was performed in layers using an interrupted suture pattern with 4.0 absorbable sutures. In this model, blood circulates from the aorta through the renal vein and to the inferior vena cava. The operative time was $45 \mathrm{~min}$ on average. All animals recovered from anesthesia within 30-45 min. Only 3 out of 40 restricted AVF-carrying animals died postoperatively within 3 days after surgery. No surgical complications or deaths were seen amongst the sham-operated animals.

\section{Hemodynamic Measurements}

The patency of the AVFs was evaluated using ultrasound biomicroscopy (Vevo 770, Visualsonics, Toronto, Ont., Canada). The blood flow was measured in the renal vein (prior to surgery) and in the fistula 0 and $6 \mathrm{~h}$ and 3, 7, 14 and 30 days after surgery with a Transonic flowmeter (Ithaca, N.Y., USA). The external diameter was measured with a ruler. The wall shear stress was calculated using the Hagen-Poiseuille formula: wall shear stress $=4 \mu \mathrm{Q} / \pi \mathrm{r} 3$ [6]. In this formula, $\mu$ is the viscosity of blood (taken to be 0.035 
Fig. 2. Histological characterization of the rat AVF. a-I Histological changes in sham-operated renal veins and AVFs. a, d The typical histology of the ligated renal vein (sham-operated rats). The successive microphotographs show the temporal histological changes in the fistula wall at 6 h (b, e), 3 days (c, f), 7 days ( $\mathbf{g}, \mathbf{j}), 14$ days $(\mathbf{h}, \mathbf{k})$ and 30 days (i, I) following surgery. All specimens were formalin-fixed and paraffin-embedded. Cross-sections were stained with hematoxylin and eosin. The boxes in $\mathbf{a}-\mathbf{c}$ and $\mathbf{g - i}$ indicate the highly magnified area in the corresponding picture below. Neointimal lesions appear between arrowheads. $\mathrm{T}=$ Thrombus associated with a necrotic neointima. $\mathbf{m}$ The fistula was divided into three sections for histomorphometric analysis (A, B and C). Arrows represent the direction of the blood flow. n, o AVF neointimal area (n) and vascular wall thickness (o) at different postsurgical times in the three sections of the AVF. Neointimal development was similar throughout the AVF venous limb. Each point represents the mean \pm SEM. The number of animals per group appears at the top of each bar in $\mathbf{n}$.

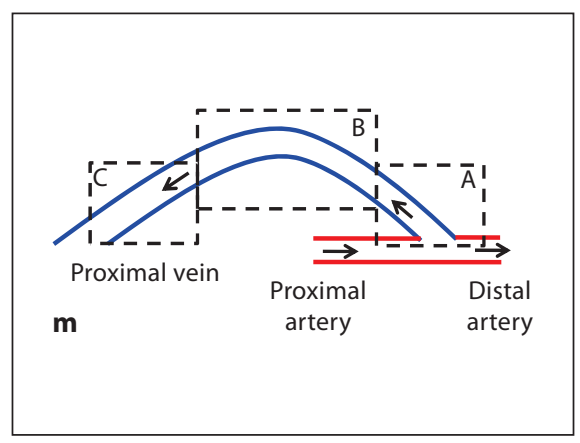

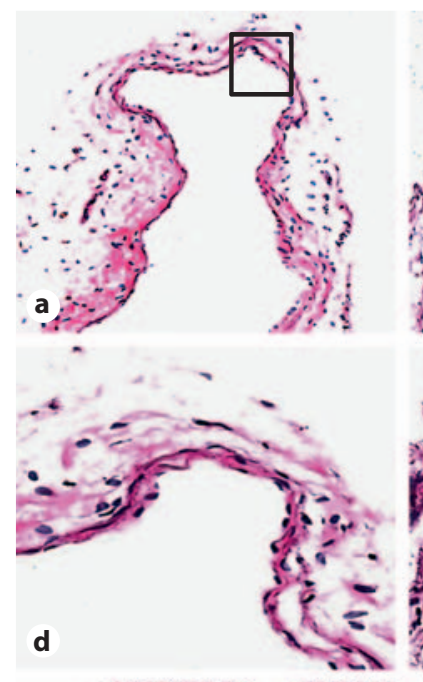
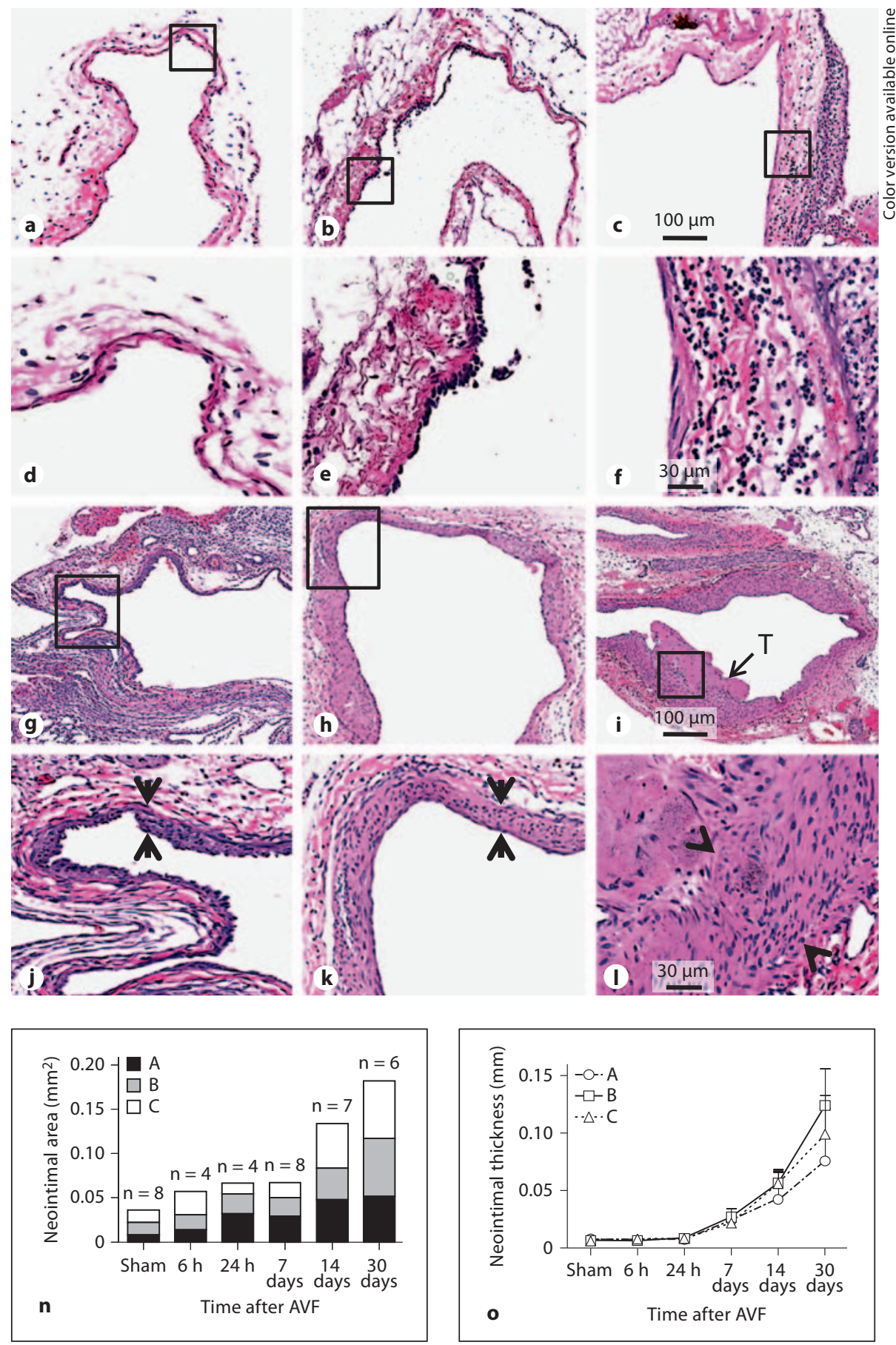

P), Q is the blood flow in milliliters per second and $r$ is $1 / 2$ of the externally measured aortic diameter without correction for wall thickness.

\section{Blood Pressure and Blood Chemistry}

Rats were anesthetized with ketamine $(20 \mathrm{mg} / \mathrm{kg})$ and xylazine $(2 \mathrm{mg} / \mathrm{kg})$, and blood pressure was measured directly in the right common carotid artery with an intra-arterial catheter. The blood pressure readings were noted 18-30 min after injecting the anesthetic, when the cardiovascular system had stabilized. The exteriorized catheter was connected to a pressure transducer for accurate measurement of blood pressure. Blood was drawn from the jugular vein for biochemical analysis. Blood urea nitrogen (BUN), creatinine, calcium and phosphorus were measured by 
Table 1. Pre- and postsurgical values for body and heart weights, blood pressure and blood chemistry of control rats (sham operation) and rats bearing a restricted AVF for 3 weeks

\begin{tabular}{|c|c|c|c|}
\hline & $\begin{array}{l}\text { Prior to } \\
\text { surgery }\end{array}$ & $\begin{array}{l}\text { Sham } \\
\text { operation }\end{array}$ & Restricted AVF \\
\hline Number & 13 & 5 & 8 \\
\hline Body weight, $g$ & $220 \pm 4.00$ & $250 \pm 6.00$ & $232 \pm 30.5^{*}$ \\
\hline $\begin{array}{l}\text { Heart weight/body } \\
\text { weight, } \mathrm{mg} / \mathrm{g}\end{array}$ & $3.01 \pm 1.02$ & $3.34 \pm 0.98$ & $5.40 \pm 2.76$ \\
\hline \multicolumn{4}{|l|}{ Blood pressure, $\mathrm{mm} \mathrm{Hg}$} \\
\hline Systolic & $121.2 \pm 7.84$ & $122.3 \pm 7.48$ & $135.3 \pm 4.48^{* *}$ \\
\hline Diastolic & $88.35 \pm 6.40$ & $87 \pm 3.37$ & $98 \pm 23.37^{* *}$ \\
\hline \multicolumn{4}{|l|}{ Blood chemistry } \\
\hline BUN, mg/dl & $12.5 \pm 2.12$ & $17.5 \pm 4.94$ & $20.5 \pm 0.70^{*}$ \\
\hline Creatinine, mg/dl & $0.4 \pm 0.14$ & $0.55 \pm 0.22$ & $0.60 \pm 0.28$ \\
\hline Calcium, mg/dl & $11.2 \pm 0.42$ & $10.55 \pm 1.48$ & $9.15 \pm 0.07$ \\
\hline Phosphorus, mg/dl & $8.95 \pm 4.45$ & $6.55 \pm 0.21$ & $7.70 \pm 0.84$ \\
\hline
\end{tabular}

Sham-operated rats underwent a unilateral nephrectomy, and the released renal vein was ligated instead of being connected to the aorta to create the fistula. ${ }^{*} \mathrm{p}<0.05$ compared to presurgical values; ${ }^{* *} \mathrm{p}<0.05$ compared to sham-operated (control) animals.

autoanalyzer techniques in the University of Miami Comparative Pathology Laboratory.

\section{Histopathology}

To examine the AVF wall for cellular and pathological changes, operated animals were sacrificed 6 h or $1,7,14$ or 30 days after surgery. Specimens were fixed in formalin and embedded in paraffin. Each fistula was divided into three sections as depicted in figure $2 \mathrm{~m}$. Multiple sections were stained with hematoxylin and eosin and Masson's trichrome for histopathological inspection. The stained slides were scanned using an Aperio ScanScope (Vista, Calif., USA), and digitalized TIFF images were uploaded to the Image-Pro Plus computer package (Media Cybernetics, Bethesda, Md., USA) to measure the lesion area and the intima-media area [12]. The number of adventitial neovessels (small arteries, veins and capillaries) was enumerated visually on hematoxylin and eosin-stained sections and further confirmed by immunostaining for endothelial cells and SMCs.

\section{Immunohistochemistry}

Immunohistochemical analysis was performed as previously reported [13]. Briefly, 5- $\mu \mathrm{M}$ paraffin sections were deparaffinized in xylene and rehydrated through a series of graded alcohol washes. After tissue rehydration, the internal peroxidase activity was quenched with hydrogen peroxide. Antigens were retrieved in 10 $\mathrm{mM}$ sodium citrate, $\mathrm{pH}$ 6.0, using a microprocessor-controlled pressure chamber (Dako, Carpinteria, Calif., USA). The nonspecific binding sites were blocked with $0.5 \%$ blocking solution (Dako). This process was followed by sequential 1-hour incubations with specific antibodies, biotinylated secondary antibodies (Dako) and streptavidin-horseradish peroxidase (HRP; Dako).
The HRP product was developed with a liquid 3,3'-diaminobenzidine-positive substrate-chromogen system (Dako). Nuclei were counterstained with Mayer's hematoxylin (Sigma-Aldrich), and sections were mounted in Entellan mounting medium (EMD, Gibbstown, N.J., USA). Primary antibodies were specific for smooth muscle actin (SMA; Dako) and von Willebrand factor (vWF; Dako).

\section{5-Bromo-2-Deoxyuridine Incorporation Assay}

5-Bromo-2-deoxyuridine (BrdU; Sigma) was administered to the rats in their drinking water $(0.8 \mathrm{mg} / \mathrm{ml}$ in water, changed daily) from day 14 to 21 [14]. A BrdU-labeling assay was performed on paraffin-embedded sections. After tissue rehydration, sections were incubated in acid alcohol ( $1 \mathrm{~N}$ acetic acid in absolute ethanol) for $30 \mathrm{~min}$ to break open the DNA. The quenching of peroxidase activity and antigen retrieval were performed as described above. Incorporated BrdU was detected with a sheep anti-BrdU polyclonal antibody (Abcam, Cambridge, UK). Sections were further incubated with a biotinylated rabbit antisheep IgG (Abcam) for $1.5 \mathrm{~h}$ and streptavidin-HRP (Dako) for $20 \mathrm{~min}$ at room temperature after rinsing off excess primary antibody. Color was developed with a 3,3'-diaminobenzidine chromogenic solution (Dako). The BrdU-labeling index (the number of BrdU-positive nuclei per unit length of internal elastic lamina corresponding to $0.1 \mathrm{~mm}$ ) was calculated from five random areas in the neointimal layer of each section.

\section{Statistical Analysis}

Data are expressed as means \pm SEM. Two-group comparison was performed using Student's t test for independent samples. Multigroup mean analysis was performed using one-way ANOVA and the Tukey-Kramer post hoc test. The GraphPad Prism 5 computer package (GraphPad Software, La Jolla, Calif., USA) was used for all statistical calculations and linear regression analysis.

\section{Results and Discussion}

Herein, we have described a unique AVF in the rat that recapitulates one of the most salient characteristics of dysfunctional human AVF, the aggressive NIH. This AVF is created by anastomosing the left renal vein to the abdominal aorta after unilateral nephrectomy. In this model, blood circulates from the aorta to the renal vein and then to the inferior vena cava. In the restricted AVF, the blood flow was controlled by placing a ligature in the distal renal vein. The postoperative survival rate of animals carrying restricted AVFs was $93.3 \%$ at 4 weeks, which is significantly better than the $50 \%$ mortality with previous aortocaval fistulae constructed by puncturing the vena cava through the lateral aortic wall with a 22 -gauge needle [15]. The control of blood flow with the distal ligature prevented excessive left ventricular hypertrophy and heart failure. Indeed, when the ligature was omitted (unrestricted fistula), $36.55 \%$ of animals died be- 
Table 2. Temporal hemodynamic changes in the rat AVF

\begin{tabular}{|c|c|c|c|c|c|c|}
\hline & \multicolumn{3}{|c|}{ Restricted AVF } & \multicolumn{3}{|c|}{ Nonrestricted AVF } \\
\hline & $\begin{array}{l}\text { blood flow } \\
\mathrm{ml} \mathrm{s}^{-1}\end{array}$ & $\begin{array}{l}\text { AVF diameter } \\
\mathrm{mm}\end{array}$ & $\begin{array}{l}\text { WSS } \\
\text { dyn } \mathrm{cm}^{-2}\end{array}$ & $\begin{array}{l}\text { blood flow } \\
\mathrm{ml} \mathrm{s}^{-1}\end{array}$ & $\begin{array}{l}\text { AVF diameter } \\
\mathrm{mm}\end{array}$ & $\begin{array}{l}\text { WSS } \\
\text { dyn } \mathrm{cm}^{-2}\end{array}$ \\
\hline Renal vein & $2.19 \pm 0.59$ & $0.15 \pm 0.00$ & $4.47 \pm 1.70$ & - & - & - \\
\hline \multicolumn{7}{|c|}{ Postsurgical time } \\
\hline 0 days & $29.99 \pm 3.24$ & $0.22 \pm 0.02$ & $16.51 \pm 3.83$ & $33.78 \pm 3.24^{*}$ & $0.21 \pm 0.02$ & $21.68 \pm 2.41^{*}$ \\
\hline 3 days & $63.03 \pm 12.60$ & $0.24 \pm 0.03$ & $36.85 \pm 20.71$ & $69.03 \pm 22.85$ & $0.22 \pm 0.08$ & $38.53 \pm 10.81$ \\
\hline 7 days & $80.22 \pm 9.25$ & $0.21 \pm 0.08$ & $49.03 \pm 7.38$ & $88.04 \pm 4.73^{*}$ & $0.22 \pm 0.01$ & $49.15 \pm 3.48$ \\
\hline 14 days & $60.52 \pm 4.28$ & $0.24 \pm 0.01$ & $25.08 \pm 10.89$ & $65.47 \pm 11.00$ & $0.22 \pm 0.03$ & $36.55 \pm 1.60^{*}$ \\
\hline 30 days & $51.22 \pm 9.27$ & $0.24 \pm 0.08$ & $21.93 \pm 8.63$ & ND & ND & ND \\
\hline
\end{tabular}

Preoperational hemodynamic parameters were similar between restricted and nonrestricted AVFs. ${ }^{*} \mathrm{p}<0.05$ compared to the corresponding values in the restricted AVF group. ND = Not determined due to inability of the animals to undergo surgery.

fore reaching the end of the experiment. Rats in the restricted flow model still developed mild cardiac hypertrophy (table 1) despite all our efforts to avoid cardiac remodeling secondary to chronic volume overload. In some respects, this could be considered positive in this model, as cardiac hypertrophy occurs in $75 \%$ of hemodialysis patients $[16,17]$.

Then, we examined the sham-operated and AVF-carrying rats for postsurgical physiological changes. We measured body weight, heart weight, blood pressure and blood chemistry in all experimental animals (table 1). The AVF-carrying rats showed a significant loss of body weight compared to sham-operated animals (250 \pm 6.00 vs. $222 \pm 30.5 \mathrm{~g} ; \mathrm{p}=0.043$ ). These rats also showed significantly elevated systolic blood pressure values compared to controls (table 1). The body weight loss and hypertension phenotypes are likely due to the mild cardiac hypertrophy [18-20]. BUN and blood creatinine levels were slightly elevated with respect to the preoperative values in all experimental animals (table 1), as previously described in uninephrectomized rats [21]. However, BUN and blood creatine levels were still much lower than those observed in hemodialysis patients [22] or in animal models of chronic kidney disease [23, 24].

We used ultrasound biomicroscopy to visualize the changes in blood flow and volume that occurred in the AVF. Figure 1c shows a representative ultrasound from an AVF at day 7. Power Doppler analysis showed highly disordered flow within all inspected fistulae $(n=7)$. Table 2 shows temporal changes in hemodynamic parameters in restricted and unrestricted AVFs. Creation of a shunt be- tween the renal vein and the aorta always produced a 10 fold increase in the fistula flow with respect to the presurgical values $(29.99 \pm 3.24$ vs. $2.19 \pm 0.59 \mathrm{ml} / \mathrm{min}$; $\mathrm{p}<0.01$ ). The magnitude of the increase in blood flow was consistent with that obtained in newly created human fistulae [25]. The blood flow was always higher in unrestricted than in restricted fistulae. In both types of fistula, the blood flow stayed high during the following 3 weeks. However, restricted fistulae were bigger in diameter than unrestricted ones, likely due to the increased intramural wall tension. In all cases, the change in the renal vein diameter was acute after surgery (150\%), and only slight enlargements were observed (3-4\%) during the subsequent weeks. The wall shear stress in both restricted and unrestricted fistulae peaked at day 7 (approx. $49 \mathrm{dyn} / \mathrm{cm}^{2}$ ), at a value nearly 3 times higher than baseline values at day $0\left(16.50 \pm 3.83 \mathrm{dyn} / \mathrm{cm}^{2}\right)$.

Next, we aimed to demonstrate the existence of histological changes in the AVF wall after its creation. Figure $2 a-1$ shows the progressive increase in the thickness of the AVF walls, with the thickest vessels seen at days 14 and 30 after surgery. Adherent leukocytes were seen as early as $6 \mathrm{~h}$ following surgery; however, leukocyte infiltration was only evident at day 3 (fig. 2c, f). A noteworthy accumulation of SMCs in the vascular wall was seen at day 7. At this time, the AVF was already 3 times thicker than the ligated renal vein of the sham-operated animals (neointimal area $0.029 \pm 0.009$ vs. $0.0084 \pm 0.0001 \mathrm{~mm}^{2}$ ). As in other animal models, some neointimas at days 7 and 14 developed bud-like protuberances [12]. No significant differences were observed among the three segments of 

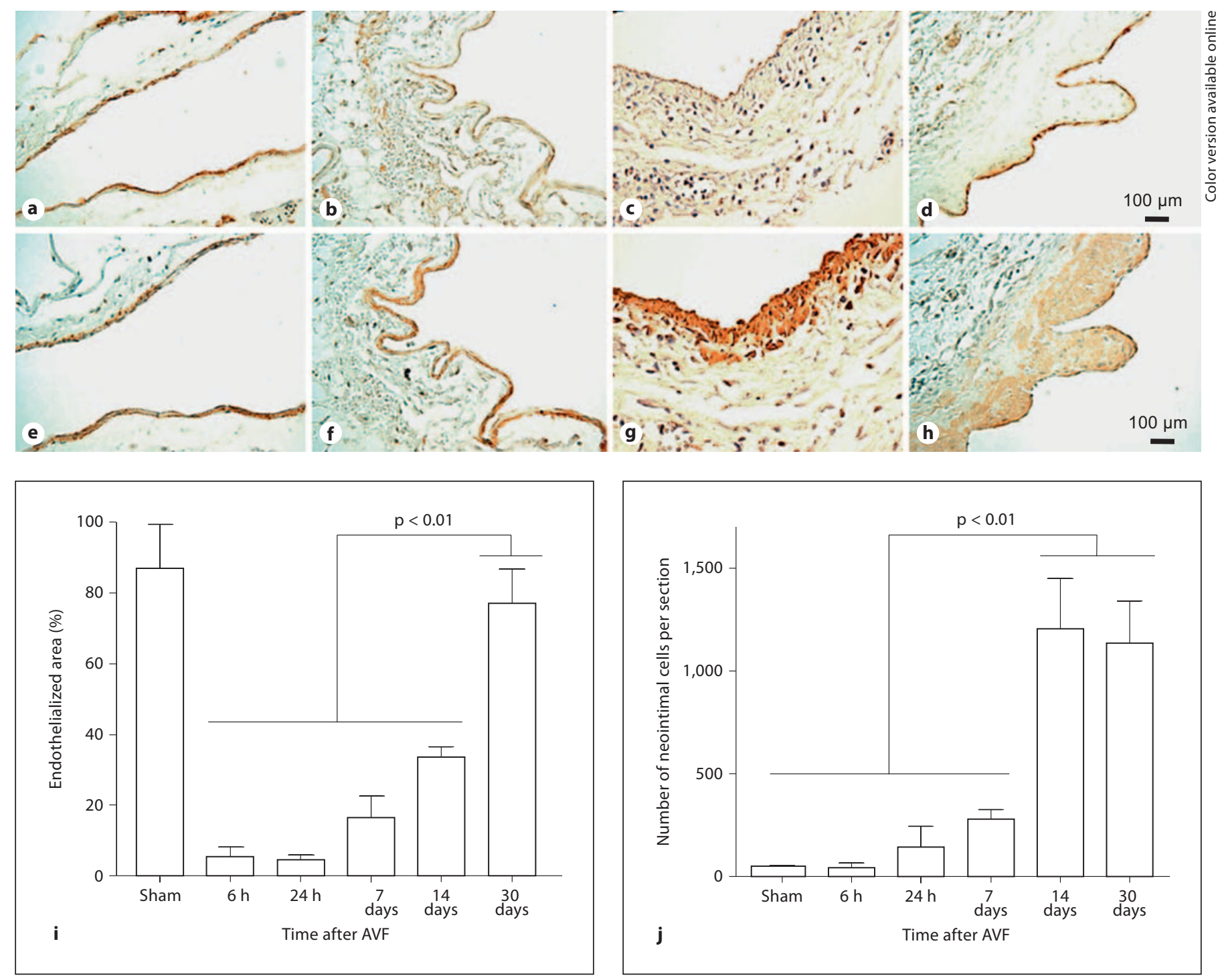

Fig. 3. Immunohistochemical analyses of the rat AVF using antibodies specific for endothelial cells and SMCs. $\mathbf{a}-\mathbf{h}$ Serial sections from sham-operated veins $(\mathbf{a}, \mathbf{e})$ and AVFs harvested at day $1(\mathbf{b}$, f), 7 (c, g) and $14(\mathbf{d}, \mathbf{h})$ were stained for endothelial cells with an anti-vWF antibody (a-d) and for SMCs with an anti-SMA antibody (e-h). Note the absence of endothelium early after fistula creation. i Quantification of the reendothelialized luminal area at

the fistula (fig. 2n, o). Interestingly, sections from the area near the juxta-anastomotic area showed a very eccentric pattern of neointima formation similar to that observed in human AVFs [26]. Although the rate of neointimal formation in our model was $100 \%$, only 4 out of 7 AVFs at 30 days contained small luminal thrombi associated with necrotic cores (fig. 2i, l). The neointimal area was similar

between unrestricted and restricted fistulae $(0.071 \pm$ 0.017 vs. $0.065 \pm 0.029 \mathrm{~mm}^{2} ; \mathrm{p}>0.12$; online supplementary fig. 1; for all online supplementary material, see www.karger.com/doi/10.1159/000332327). The neointima in our model was thicker than that in rat tail and femoral fistulae in other reports $[9,27]$. There was a progressive accumulation of collagen and smooth muscle in 


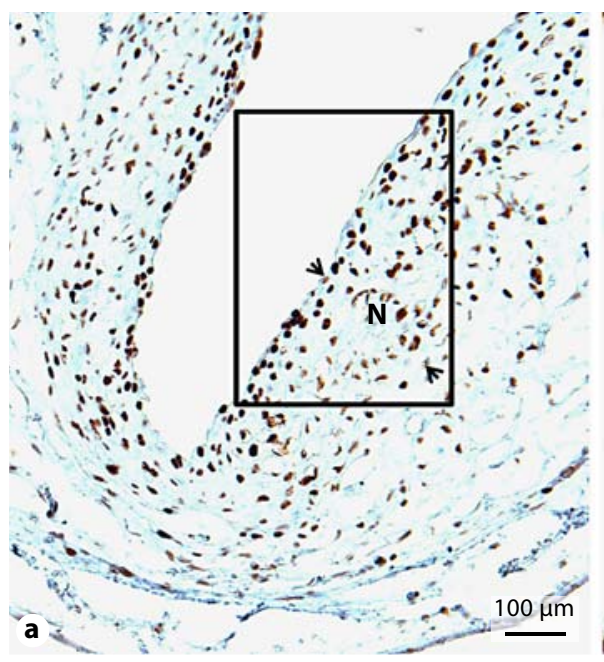

Fig. 4. Proliferating neointimal cells in the venous limb of the fistula. a AVF neointima stained for BrdU, a marker for proliferating cells. BrdU, which is a thymidine analog that is selectively incorporated into the DNA of proliferating cells, was administered to the rats between day 14 and 21 after fistula creation. BrdU-posi-

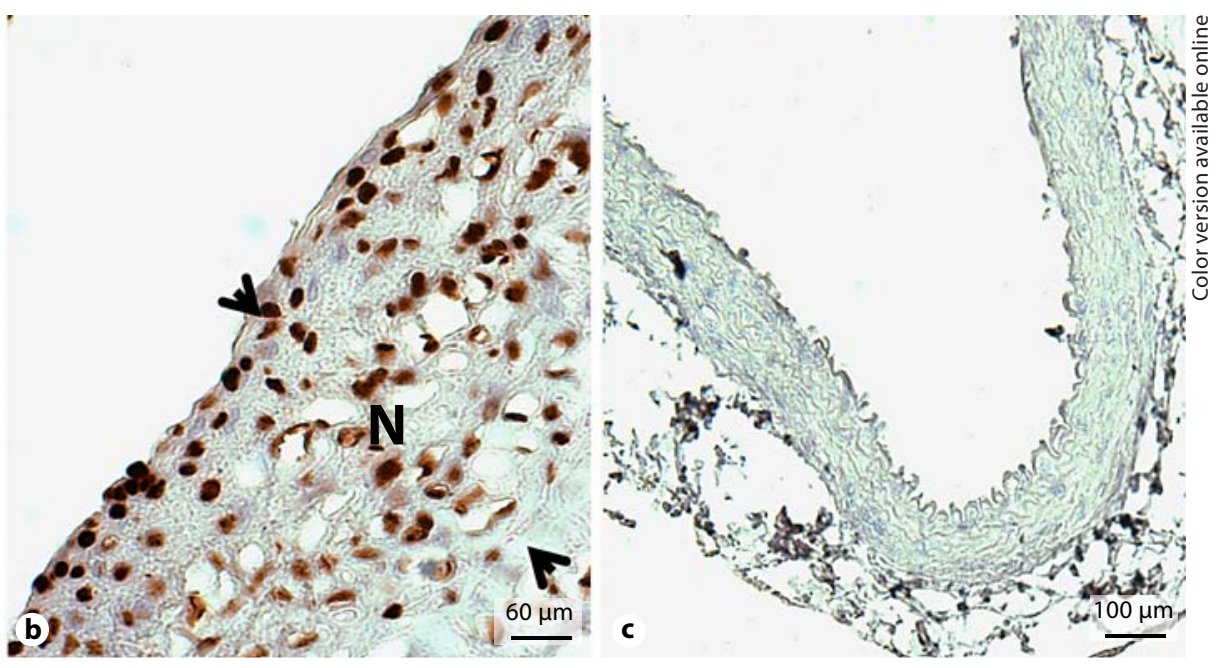

tive nuclei appear as brown spots. The neointima $(\mathrm{N})$ is marked between arrowheads. $\mathbf{b}$ High-power view of the neointimal area within the rectangle in a. c An AVF feeding artery stained for BrdU. No BrdU-positive cells were seen in the feeding artery. the tunica media layer of the arterialized veins between days 7 and 30 (online suppl. fig. 2).

To further characterize the histological changes that occurred in our experimental fistulae, we stained serial sections taken from the anastomosis point of a blood-restricted AVF with antibodies specific for SMCs (SMA) and endothelial cells (vWF). Flow-induced endothelial injury was observed after fistula creation on day 1 (fig. 3b). Endothelial repair was only observed in the vascular wall after day 7. At day 14, most of the luminal surface of the fistula was endothelialized (fig. 3d). However, the presence of endothelial cells did not stop SMC accumulation in the vein (fig. $3 \mathrm{f}-\mathrm{h}$ ). Neointimal cells were evident at day 7 and increased in number during the following weeks to cause a significant vein stenosis $(27 \pm 10.5 \%)$. Human stented coronary arteries contain an endothelium that prevents thrombosis but not the development of restenotic lesions [28]. An impressive number of those neointimal cells were positive for $\mathrm{BrdU}(76.35 \pm 23.4 ; \mathrm{n}=4)$, revealing highly proliferative activity in the rat AVF neointima between 2 and 3 weeks after fistula creation (fig. 4). Inspection of human fistulae for the expression of the proliferative marker proliferating cell nuclear antigen has found a high proliferative index that ranged between 10 and $25 \%$ of the total number of cells $[26,29]$. Similar results have been observed in experimental fistulae in pigs [12].
Finally, we assessed the development of adventitial neoangiogenesis in the renal vein after AVF creation. New microvessel formation emanating from the vasa vasorum of the adventitia has been associated with neointimal formation and atherosclerotic plaque growth [30,31]. In the restricted fistulae, the number of adventitial blood vessels in the AVF correlated with the development of $\mathrm{NIH}(\mathrm{r}=0.8903, \mathrm{p}=0.001$; fig. 5f). A similar correlation was found in the unrestricted fistulae $(r=0.791, p=001)$. The number of vessels increased gradually from $13 \pm 3$ vessels on day 1 to $204 \pm 43$ on day 30 following surgery (fig. $5 \mathrm{a}-\mathrm{c})$. The neovasculature was composed of small arteries, veins and numerous capillaries that stained positively for SMA and/or vWF (fig. 5d, e).

\section{Limitations}

Our model has its own virtues and limitations. Its major limitations are as follows: (1) the demanding microsurgical skills that are required to anastomose the renal vein directly into the arterial circulation; (2) the anatomical location of the fistula in the abdominal cavity, which differs from human superficial fistulae; (3) the lack of chronic kidney disease, which causes adverse remodeling in arterialized veins [24]; (4) the superimposed stenosis to control blood flow and heart failure, and (5) the mild ven- 


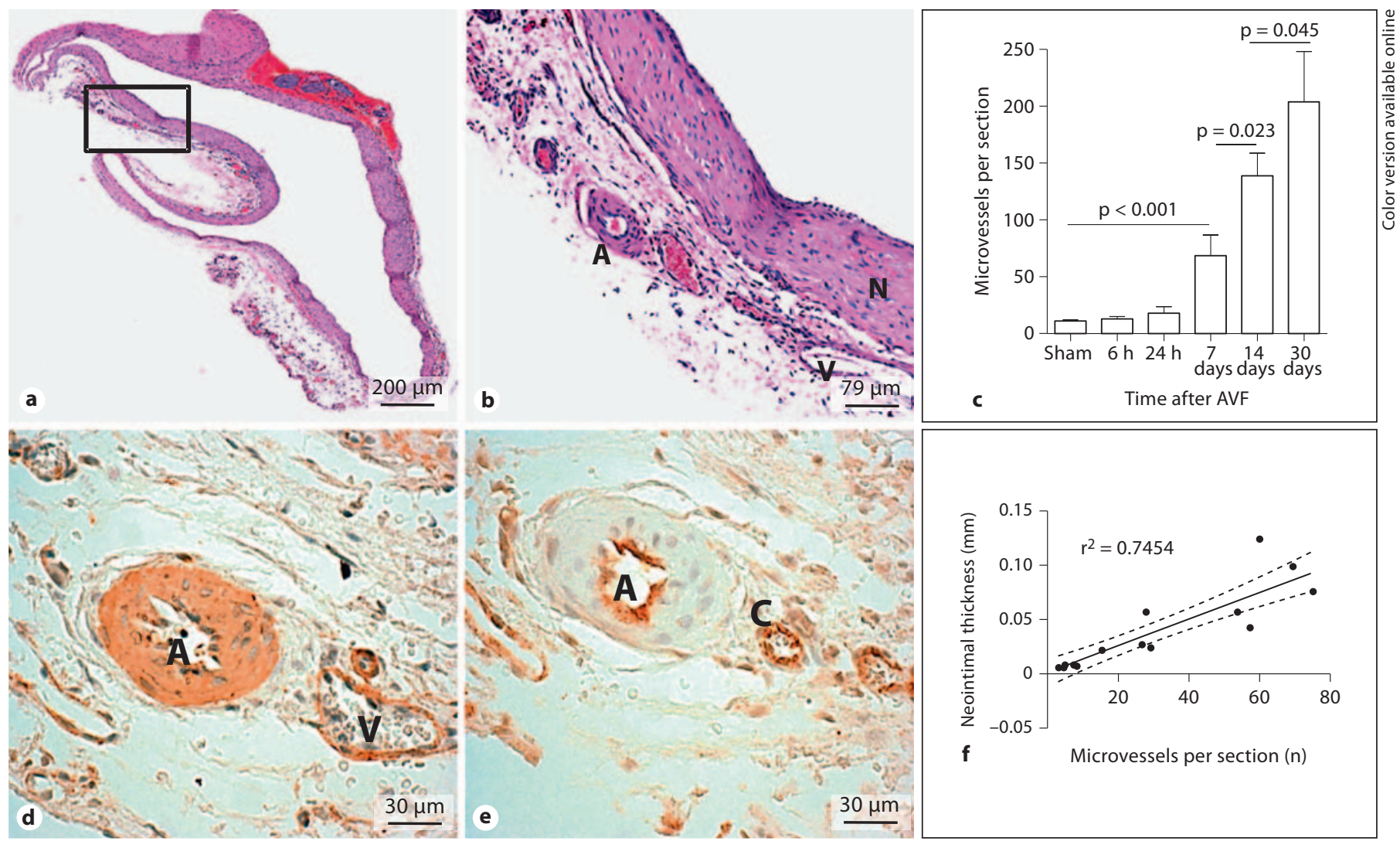

Fig. 5. Neoangiogenesis in the AVF vascular wall. a, b Low- (a) and high-power (b) views of a representative AVF at day 14. The section was stained with hematoxylin and eosin and shows marked neovascularization around the fistula wall. The rectangle in a indicates the magnified area in b. c Quantification of adventitial blood vessels in the venous limb of the fistula at different times following surgery. Each bar represents the mean \pm SEM of values from 4-8 animals. The number of animals in each group is the same as shown in figure $2 \mathrm{p}$. $\mathrm{p}$ values were calculated using one-way ANOVA and the Tukey-Kramer post hoc test. d, e Immunohistochemistry to demonstrate the presence of endothelial cells (e) and SMCs (d) in the neovasculature around the fistula wall. A = Arteriole; $\mathrm{V}=$ small vein; $\mathrm{C}=$ capillary. $\mathbf{f}$ Linear regression analysis comparing neointimal area versus the number of microvessels per section. A strong relationship was observed between adventitial neovascularization and the development of $\mathrm{NIH}$. tricular hypertrophy that developed in some animals and that increases mortality after 45 days. Most of these limitations are inherent to experimental fistulae in rodents, and none of them compromise the development of NIH and the arterialization of the vein, which are the ultimate goals of our model. Previous fistulae in rodents made by joining the aorta with the vena cava $[6,7,10]$, carotid and jugular veins [9] and femoral vessels [27] were not superficial and visible, and all required excellent microsurgical skills for creation. Of note, chronic kidney disease could easily be added to our model by partially ligating the renal arteries (5/6 nephrectomy) of the remaining kidney [32]. On the other hand, we have proved that the superimposed stenosis can be omitted without modifying the desired histological changes in the vein.

\section{Conclusion}

The alternative experimental AVF described herein resembles human fistulae in terms of the site of stenosis and neointimal thickness. Importantly, the model provides a simple means of studying NIH.

\section{Acknowledgements}

We thank Lucinda Greenaway and Irene Hung for clerical assistance. We thank Dimitrios Kasdaglis (http://dimkas.deviantart.com/) for the artwork in figure 1a. This work was supported by a grant from the National Heart, Lung, and Blood Institute (1K01HL096413-01) to R.I.V.-P. 


\section{References}

-1 Mercado C, Salman L, Krishnamurthy G, Choi K, Artikov S, Thomas I, Merrill D, Asif A: Early and late fistula failure. Clin Nephrol 2008;69:77-83.

-2 Lee H, Manns B, Taub K, Ghali WA, Dean S, Johnson D, Donaldson C: Cost analysis of ongoing care of patients with end-stage renal disease: the impact of dialysis modality and dialysis access. Am J Kidney Dis 2002;40: 611-622.

-3 Roy-Chaudhury P, Spergel LM, Besarab A, Asif A, Ravani P: Biology of arteriovenous fistula failure. J Nephrol 2007;20:150-163.

-4 Dember LM, Beck GJ, Allon M, Delmez JA, Dixon BS, Greenberg A, Himmelfarb J, Vazquez MA, Gassman JJ, Greene T, Radeva MK, Braden GL, Ikizler TA, Rocco MV, Davidson IJ, Kaufman JS, Meyers CM, Kusek JW, Feldman HI: Effect of clopidogrel on early failure of arteriovenous fistulas for hemodialysis: a randomized controlled trial. JAMA 2008;299:2164-2171.

5 Roy-Chaudhury P, Wang Y, Krishnamoorthy M, Zhang J, Banerjee R, Munda R, Heffelfinger S, Arend L: Cellular phenotypes in human stenotic lesions from haemodialysis vascular access. Nephrol Dial Transplant 2009;24:2786-2791.

6 Guzman RJ, Krystkowiak A, Zarins CK: Early and sustained medial cell activation after aortocaval fistula creation in mice. J Surg Res 2002;108:112-121.

7 Chang CJ, Chen CC, Hsu LA, Chang GJ, Ko YH, Chen CF, Chen MY, Yang SH, Pang JHS: Degradation of the internal elastic laminae in vein grafts of rats with aortocaval fistulae: potential impact on graft vasculopathy. Am J Pathol 2009;174:1837-1846.

8 Chan CY, Chen YS, Ma MC, Chen CF: Remodeling of experimental arteriovenous fistula with increased matrix metalloproteinase expression in rats. J Vasc Surg 2007;45:804-811.

-9 Castier Y, Lehoux S, Hu Y, Foteinos G, Tedgui A, Xu Q: Characterization of neointima lesions associated with arteriovenous fistulas in a mouse model. Kidney Int 2006;70:315-320.

10 Caplice NM, Wang S, Tracz M, Croatt AJ, Grande JP, Katusic ZS, Nath KA: Neoangiogenesis and the presence of progenitor cells in the venous limb of an arteriovenous fistula in the rat. Am J Physiol Renal Physiol 2007;293:F470-F475

- 11 Lin T, Horsfield C, Robson MG: Arteriovenous fistula in the rat tail: a new model of hemodialysis access dysfunction. Kidney Int $2008 ; 74: 528-531$
12 Wang Y, Krishnamoorthy M, Banerjee R, Zhang J, Rudich S, Holland C, Arend L, RoyChaudhury P: Venous stenosis in a pig arteriovenous fistula model - anatomy, mechanisms and cellular phenotypes. Nephrol Dial Transplant 2008;23:525-533.

13 Khan SJ, Pham S, Wei Y, Mateo D, St-Pierre M, Fletcher TM, Vazquez-Padron RI: Stressinduced senescence exaggerates postinjury neointimal formation in the old vasculature. Am J Physiol Heart Circ Physiol 2010;298: H66-H74.

14 Calfa M, Aitouche A, Vazquez-Padron RI, Gay-Rabinstein C, Lasko D, Badell J, Farji A, El-Haddad A, Liotta C, Louis LB, Simmonds A, Pestana IA, Pang M, Li S, Pham SM: Aging and transplant arteriosclerosis in absence of alloreactivity and immunosuppressive drugs in a rat aortic model: recipient age's contribution. Transplantation 2005;79: 1683-1690.

15 Brower GL, Janicki JS: Contribution of ventricular remodeling to pathogenesis of heart failure in rats. Am J Physiol Heart Circ Physiol 2001;280:H674-H683.

16 Sarnak MJ, Levey AS: Cardiovascular disease and chronic renal disease: a new paradigm. Am J Kidney Dis 2000;35:S117-S131.

17 Levin A, Foley RN: Cardiovascular disease in chronic renal insufficiency. Am J Kidney Dis 2000;36:S24-S30.

18 Flaim SF, Minteer WJ, Nellis SH, Clark DP: Chronic arteriovenous shunt: evaluation of a model for heart failure in rat. Am J Physiol 1979;236:H698-H704.

$\checkmark 19$ Liu Z, Hilbelink DR, Crockett WB, Gerdes AM: Regional changes in hemodynamics and cardiac myocyte size in rats with aortocaval fistulas. 1. Developing and established hypertrophy. Circ Res 1991;69:52-58.

20 Garcia R, Diebold S: Simple, rapid, and effective method of producing aortocaval shunts in the rat. Cardiovasc Res 1990;24:430-432.

21 Tomita M, Sogabe H, Nakazato S, Nakatsuji S, Noto T, Hamada K, Kawachi H, Shimizu F, Matsuo M, Mutoh S: Monoclonal antibody 1-22-3-induced glomerulonephritis in uninephrectomized rats as a model of progressive renal failure. Nephrol Dial Transplant 2005;20:2358-2367.
22 Frankenfield DL, McClellan WM, Helgerson SD, Lowrie EG, Rocco MV, Owen WF Jr: Relationship between urea reduction ratio, demographic characteristics, and body weight for patients in the 1996 National ESRD Core Indicators Project. Am J Kidney Dis 1999;33: 584-591.

23 Kokubo T, Ishikawa N, Uchida H, Chasnoff SE, Xie X, Mathew S, Hruska KA, Choi ET: CKD accelerates development of neointimal hyperplasia in arteriovenous fistulas. J Am Soc Nephrol 2009;20:1236-1245.

24 Langer S, Kokozidou M, Heiss C, Kranz J, Kessler T, Paulus N, Kruger T, Jacobs MJ, Lente C, Koeppel TA: Chronic kidney disease aggravates arteriovenous fistula damage in rats. Kidney Int 2010;78:1312-1321.

-25 Asif A, Roy-Chaudhury P, Beathard GA: Early arteriovenous fistula failure: a logical proposal for when and how to intervene. Clin J Am Soc Nephrol 2006;1:332-339.

26 Roy-Chaudhury P, Arend L, Zhang J, Krishnamoorthy M, Wang Y, Banerjee R, Samaha A, Munda R: Neointimal hyperplasia in early arteriovenous fistula failure. Am J Kidney Dis 2007;50:782-790.

27 Croatt AJ, Grande JP, Hernandez MC, Ackerman AW, Katusic ZS, Nath KA: Characterization of a model of an arteriovenous fistula in the rat: the effect of L-NAME. Am J Pathol 2010;176:2530-2541.

28 Anderson PG, Bajaj RK, Baxley WA, Roubin GS: Vascular pathology of balloon-expandable flexible coil stents in humans. J Am Coll Cardiol 1992;19:372-381.

29 Rekhter M, Nicholls S, Ferguson M, Gordon $\mathrm{D}$ : Cell proliferation in human arteriovenous fistulas used for hemodialysis. Arterioscler Thromb 1993;13:609-617.

30 Gossl M, Herrmann J, Tang H, Versari D, Galili O, Mannheim D, Rajkumar SV, Lerman LO, Lerman A: Prevention of vasa vasorum neovascularization attenuates early neointima formation in experimental hypercholesterolemia. Basic Res Cardiol 2009;104: 695-706.

31 Doyle B, Caplice N: Plaque neovascularization and antiangiogenic therapy for atherosclerosis. J Am Coll Cardiol 2007;49:20732080.

32 Fleck C, Appenroth D, Jonas P, Koch M, Kundt G, Nizze H, Stein G: Suitability of $5 / 6$ nephrectomy (5/6NX) for the induction of interstitial renal fibrosis in rats - influence of sex, strain, and surgical procedure. Exp Toxicol Pathol 2006;57:195-205. 